\title{
Физико-химические и селективные свойства гетерогенных ионообменных мембран МК-40 и МА-40 после электродиализа природных вод
}

\author{
Акберова Э.М., Васильева В.И., Смагин М.А., Костылев Д.В. \\ ФГБОУ ВО «Воронежский государственный университет», Воронеж
}

Поступила в редакцию 18.06.2019 г.

DOI: https://doi.org/10.17308/sorpchrom.2019.19/781

Установлено влияние структурных изменений и образования осадков после электродиализа природных вод на равновесные и селективные свойства гетерогенных ионообменных мембран МК-40 и МА-40. Образование малорастворимых осадков на поверхности и в объеме мембран, извлеченных из электродной секции реверсивного электродиализатора, приводит к блокировке функциональных групп и транспортных каналов, уменьшению обменной емкости, влагосодержания и чисел переноса противоионов, затруднению процессов переноса. Для мембраны из электродиализатораконцентратора выявлено увеличение макропористости, которое является основной причиной роста влагосодержания на фоне потери обменной емкости и селективности.

Ключевые слова: гетерогенная ионообменная мембрана, числа переноса, электродиализ, природные воды, микроструктура, осадкообразование.

\section{Physicochemical and selective properties of heterogeneous ion-exchange membranes MK-40 and MA-40 after electrodialysis of natural water}

\author{
Akberova E.M., Vasil'eva V.I., Smagin M.A., Kostylev D.V. \\ Voronezh State University, Voronezh
}

\begin{abstract}
The method of electrodialysis is quite effective and environmentally appropriate, a known limitation of the applicability of which is the rapid decrease in the electrochemical activity of membranes under the influence of polarization and temperature effects, as well as sedimentation during the process. The purpose of this work was to study the changes in the physicochemical and selective properties of heterogeneous ionexchange membranes during long-term operation in electrodialysis equipment during desalting and concentration of mineralized natural waters.

Structural changes of the heterogeneous membranes after continuous operation in the electrodialyzers of different types were evaluated by the scanning electron microscopy. Information on the chemical composition of the membrane surface or cross section was obtained by mapping the elemental composition using an energy dispersive spectrometer. The physicochemical characteristics of membranes were identified by the standard procedures.

The influence of structural changes and the formation of precipitation after electrodialysis of natural water on the equilibrium and selective properties of heterogeneous ion-exchange membranes MK-40 and MA-40 was established. The formation of poorly soluble precipitates on the surface and in the bulk of the membranes extracted from the electrode section of the reversal electrodialyzer leads to blocking of the functional groups and transport channels, reduction of the exchange capacity, water content and transport numbers of counter ions, preventing the transfer processes. An increase in macroporosity was revealed for the
\end{abstract}


membrane from the electrodialyzer-concentrator, which is the main cause of the growth of water content against the background of loss of exchange capacity and selectivity.

Keywords: heterogeneous ion-exchange membrane, transport numbers, electrodialysis, natural water, microstructure, precipitation

\section{Введение}

Метод электродиализа является достаточно эффективным и экологически целесообразным, однако известным ограничением применимости метода является быстрое снижение электрохимической активности мембран в ходе процесса. Эксплуатационная эффективность электромембранных систем водоподготовки лимитируется, в основном, снижением электрохимической активности мембран под воздействием поляризационных и температурных эффектов, а также осадкообразования. Современные гетерогенные ионообменные мембраны имеют срок службы от двух до пяти лет. Стоимость при замене мембран по окончанию эксплуатации составляет вторую, после стоимости энергозатрат, статью электродиализных расходов [1]. В электродиализаторах при деминерализации природных вод вероятность образования осадков прямо связана с величиной рН [2-4]. Дополнительным фактором, влияющим на образование осадка, является соотношение осадкообразующих ионов из-за их конкуренции во время миграции из секции с дилюатом в секцию с концентратом и из-за перекрестного влияния различных осадкообразующих ионов на образование и рост кристаллов $[2,3,5,6]$. Сравнение осадкообразования на гомогенных и гетерогенных мембранах и возможности его предотвращения было показано в [7-9]. В работе [9] было обнаружено, что осадок гипса $\left(\mathrm{CaSO}_{4} \cdot 2 \mathrm{H}_{2} \mathrm{O}\right)$ растет в основном в объеме гетерогенной мембраны MA-40, в то время как для гомогенной мембраны AMV - в основном на поверхности мембраны, обращенной к секции концентрата. На поверхности мембраны МА-40 осадок локализован на токопроводящих участках и его количество по сравнению с гомогенной мембраной выше.

Целью настоящей работы явилось исследование изменений физикохимических и селективных свойств гетерогенных ионообменных мембран в процессе длительной эксплуатации в электродиализных аппаратах при обессоливании и концентрировании минерализованных природных вод.

\section{Эксперимент}

Объекты исследования. Объектами исследования являлись образцы катионообменной мембраны МК-40 и анионообменной мембраны МА-40 после стандартной процедуры кондиционирования и после длительного применения в промышленных электродиализаторах в режиме обессоливания/концентрирования природных вод. Исследуемые гетерогенные мембраны изготавливают методом горячего прессования, и они представляют собой композиты из ионообменных смол, полиэтилена низкого давления и армирующей ткани (капрон). Мембрана МК-40 состоит из композиции на основе сильнокислотного ионита КУ-2 (65\%) с сульфогруппами в качестве ионогенных групп, мембрана МА-40 - на основе полифункционального (смешанной основности) анионита ЭДЭ-10П. Фиксированными группами являются вторичные $\mathrm{NH}\left(\mathrm{CH}_{3}\right)_{2}{ }^{+}$и третичные $\mathrm{NH}_{2}\left(\mathrm{CH}_{3}\right)^{+}$аминогруппы, а также четвертичные аммониевые группировки - $\mathrm{N}^{+}\left(\mathrm{CH}_{3}\right)_{3}$ в количестве до $20 \%$ [10]. Физико-химические характеристики и селективные свойства мембран после эксплуатации сравнивали с образцами мембран, кондиционированными по стандартным методикам [11].

Были исследованы образцы мембран из электродных секций реверсивного электродиализатора после работы при обессоливании природных вод Аральского 
региона с высоким значением жесткости в течение 1000 ч. В составе вод содержится большое количество хлоридов и сульфатов [12]. Во все секции электродиализатора подавали природные минерализованные воды. При общем содержании солей 12.87 г/дм ${ }^{3}$ и жесткости 49 ммоль/дм ${ }^{3}$ содержание натрия составило 3.91, калия - 0.023, кальция -0.313 , магния -0.400 , гидрокарбонатов -0.183 , сульфатов -1.368 , хлоридов -6.671 г/дм ${ }^{3}, \mathrm{pH} 7.5$.

Образцы мембран, извлеченные из середины рабочего пакета аппарата-

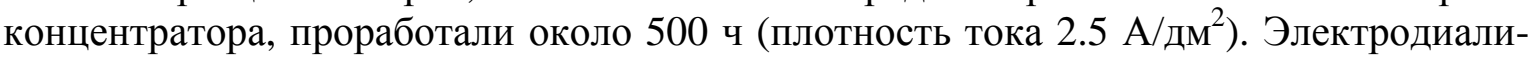
затор-концентратор с непроточными камерами концентрирования был использован без реверса тока для получения рассолов концентрации 180-200 г/дм ${ }^{3}$ [13] из подземной воды хлоридного класса. Общее содержание солей составило 17.29 г/дм $^{3}$ при жесткости 52 ммоль/дм ${ }^{3}$ и рН 7.3. В составе обрабатываемой воды натрия содержалось 5.732, магния - 0.381, кальция -0.417 , гидрокарбонатов -0.189 , хлоридов 10.582 г/дм ${ }^{3}$. Ресурсные испытания аппарата-концентратора проведены ТОО «Мембранные технологии, С.А.» [14] в Тюменской области, им же предоставлены образцы для исследований.

Методы исследования равновесных, селективных и структурных свойств мембран. Влагосодержание $W$ мембран контролировали методом воздушно-тепловой сушки, толщину $d$ определяли с точностью до 1 мкм микрометрическим методом, плотность $\rho$ измеряли пикнометрическим методом [11]. Полную обменную емкость мембран $Q$ оценивали методом кислотно-основного титрования в статических условиях определением общего количества противоионов, вступивших в ионный обмен по реакции нейтрализации.

Числа переноса противоионов в мембранах определяли потенциометрическим методом из экспериментально измеренной разности мембранных потенциалов ячейки, которая содержала обратимые электроды, мембрану и растворы с разной концентрацией электролита по обе стороны мембраны [15].

Поверхность сухих и набухших образцов мембран исследовали методом растровой электронной микроскопии (РЭМ). Прибор JSM-6380 LV (Япония) оснащен энергодисперсионным анализатором элементного состава и регулятором давления в камере с исследуемым образцом. Информация о химическом составе поверхности или сечения мембраны получена картированием элементного состава с использованием энергодисперсионного спектрометра. Цветокодирование для визуализации рентгеновского спектра дало возможность скомбинировать на одном изображении данные по нескольким элементам.

Количественная оценка доли порового состава на поверхности и срезе мембран проводилась с помощью авторского программного комплекса [16]. Долю макропор на поверхности мембраны определяли согласно $P=\left(\Sigma S_{i} / S\right) \cdot 100 \%$, где $\Sigma S_{i}-$ суммарная площадь макропор, $S$ - площадь сканируемого участка. Под радиусом поры $r$ понимали эффективный радиус моделируемого программой участка круглой формы, который по площади эквивалентен площади реальной поры произвольной формы. При вычислении среднего радиуса для учета различной доли пор с отличающимися размерами использовали средневзвешенное значение [17].

\section{Обсуждение результатов}

Основные физико-химические характеристики образцов сульфокатионообменной мембраны МК-40 и анионообменной мембраны МА-40 после кондиционирования и работы в электродиализаторах разного типа представлены в табл. 1. 
Таблица 1. Равновесные характеристики образцов гетерогенных ионообменных мембран после кондиционирования и эксплуатации в электродиализаторах разного типа

\begin{tabular}{|c|c|c|c|c|c|}
\hline $\begin{array}{c}\text { Мембра- } \\
\text { на }\end{array}$ & Образец мембраны & $\mathrm{Q}$, ммоль/г & $\begin{array}{c}\text { Влагосодер- } \\
\text { жание W, \% }\end{array}$ & $\begin{array}{c}\text { Толщи- } \\
\text { на, мкм }\end{array}$ & $\begin{array}{c}\text { Плотность, } \\
\text { г/см }\end{array}$ \\
\hline \multirow{3}{*}{ МК-40 } & Кондиционированный & $1.52 \pm 0.08$ & $33 \pm 1$ & $520 \pm 10$ & 1.19 \\
\cline { 2 - 6 } & $\begin{array}{c}\text { Аппарат- } \\
\text { концентратор }\end{array}$ & $1.38 \pm 0.06$ & $38 \pm 1$ & $530 \pm 10$ & 1.11 \\
\cline { 2 - 6 } & $\begin{array}{c}\text { Реверсивный элек- } \\
\text { тродиализатор }\end{array}$ & $1.29 \pm 0.06$ & $31 \pm 1$ & $560 \pm 5$ & 1.19 \\
\hline \multirow{2}{*}{ МА-40 } & Кондиционированный & $2.71 \pm 0.09$ & $38 \pm 3$ & $560 \pm 20$ & 1.19 \\
\cline { 2 - 6 } & $\begin{array}{c}\text { Аппарат- } \\
\text { концентратор }\end{array}$ & $2.47 \pm 0.09$ & $43 \pm 2$ & $580 \pm 10$ & 1.10 \\
\cline { 2 - 6 } & $\begin{array}{c}\text { Реверсивный элек- } \\
\text { тродиализатор }\end{array}$ & $2.20 \pm 0.08$ & $35 \pm 1$ & $505 \pm 5$ & 1.20 \\
\hline
\end{tabular}

Из сравнения значений полной обменной емкости отработанных и кондиционированных мембран следует, что сульфокатионообменные мембраны характеризуются большей стабильностью, чем анионообменные. Основной причиной частичной потери обменной емкости мембран МК-40 является процесс термического десульфирования [18, 19] достаточно термостабильных фиксированных сульфогрупп вследствие воздействия продуктов электролиза и перегрева. Потеря обменной емкости мембраны МА-40 связана с деградацией активных групп анионообменника ЭДЭ10П. На основании термографических данных в работах [20, 21] выявлены различия в устойчивости слабо- и сильноосновных групп анионита ЭДЭ-10П и установлено, что уменьшение обменной емкости проходит в основном по группам высокой основности. При нагревании в воде происходят реакции дезаминирования (отщепление от полимерной матрицы четвертичного амина) и деградации с образованием третичных и вторичных аминогрупп $[22,23]$. Кроме того, термодеструкция поликонденсационного полиаминного анионообменника ЭДЭ-10П, на основе которого изготовлена мембрана МА-40, может происходить по следующему механизму [24]: на начальной стадии происходит разрыв связи углерод-третичный азот с миграцией подвижного метиленового водорода к месту разрыва.

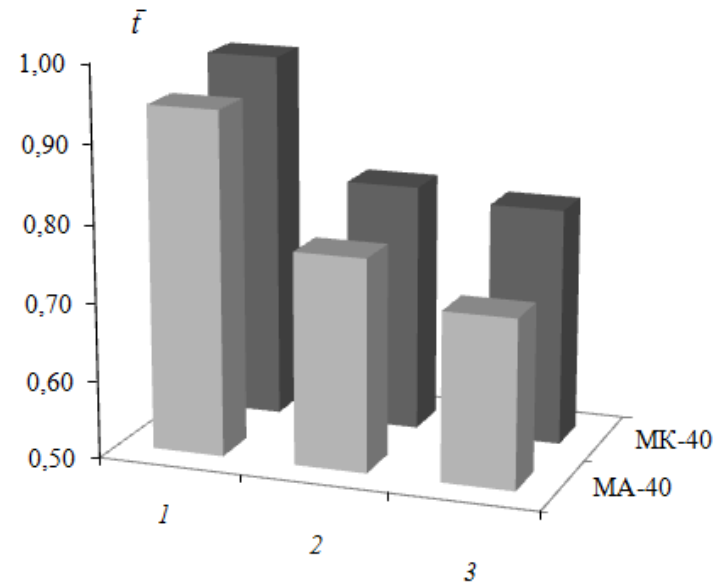

Рис. 1. Потенциометрические числа переноса противоионов в мембранах МК-40 и MA-40. Образцы: кондиционированный (1); из аппарата-концентратора (2); из электродной секции реверсивного электродиализного аппарата (3) 
На рис. 1 представлены величины чисел переноса противоионов гетерогенных ионообменных мембран после кондиционирования и длительной эксплуатации в электродиализаторах разного типа. Для всех исследованных образцов мембран выявлено уменьшение селективности. Максимальными изменениями чисел переноса противоионов характеризовалась анионообменная мембрана, извлеченная из анодной секции реверсивного электродиализатора, а минимальные изменения были выявлены для мембраны МК-40 из рабочего пакета аппарата-концентратора без реверса тока.

Изменение селективности может происходить вследствие действия двух факторов: за счет изменения обменной емкости мембран из-за трансформации состава функциональных групп или их блокировки и за счет изменения микроструктуры мембран.

Существенное увеличение объема гидрофильных неселективных пор и дефектов структуры, которые служат для одноименно заряженных ионов каналами переноса, приводит к снижению селективности мембран из электродиализатораконцентратора на фоне частичной потери обменной емкости и роста влагосодержания [25]. Результаты количественной оценки порового состава поверхности мембран (табл. 2) свидетельствуют об изменениях микроструктуры, связанных с увеличением макропористости и появлением дефектов структуры из-за деструкции ионообменника и инертного связующего полиэтилена в результате эксплуатации. После эксплуатации мембран при концентрировании природных вод Тюменской области минеральные отложения практически не визуализируются.

Таблица 2. Структурные характеристики набухших образцов гетерогенных ионообменных мембран после кондиционирования и эксплуатации в электродиализаторах разного типа

\begin{tabular}{|c|c|c|c|}
\hline Мембрана & Образец мембраны & $P, \%$ & $\bar{r}$, мкм \\
\hline \multirow{3}{*}{ МК-40 } & Кондиционированный & 1.9 & 1.81 \\
\cline { 2 - 4 } & Аппарат-концентратор & 2.2 & 1.80 \\
\cline { 2 - 4 } & $\begin{array}{c}\text { Реверсивный электродиализа- } \\
\text { тор }\end{array}$ & 2.0 & 2.16 \\
\hline \multirow{3}{*}{ МА-40 } & Кондиционированный & 2.2 & 2.53 \\
\cline { 2 - 4 } & Аппарат-концентратор & 2.8 & 2.90 \\
\cline { 2 - 4 } & $\begin{array}{c}\text { Реверсивный электродиализа- } \\
\text { тор }\end{array}$ & 2.4 & 2.41 \\
\hline
\end{tabular}

$P$ - доля макропор на поверхности; $\bar{r}$ - средневзвешенный радиус макропор на поверхности.

Вероятной причиной снижения чисел переноса противоионов мембран, проработавших в электродных секциях реверсивного электродиализатора, является осадкообразование, затрагивающее поверхность и объем мембраны [26].

РЭМ-изображения поверхности образцов мембран МК-40 и МА-40 из электродных секций реверсивного электродиализатора представлены на рис. 2. На поверхности мембран визуализируется образование осадка, который локализован не только в областях с хорошей электропроводностью, где находятся частицы ионообменника, а покрывает пленкой практически всю поверхность.

Результаты рентгеноспектрального микроанализа компонентного состава пленки осадка на поверхности мембраны МК-40 из реверсивного электродиализного аппарата показали преимущественное содержание Са (16.17 мас. \%) и присутствие элементов $\mathrm{Mg}$ (1.25 мас. \%), Fe (1.28 мас. \%), Si (0.05 мас. \%). В соответствии с составом очищаемой воды Аральского региона, содержащей ионы $\mathrm{Ca}^{2+}, \mathrm{Mg}^{2+}, \mathrm{SO}_{4}^{2-}$, 
$\mathrm{HCO}_{3}^{-}$у поверхности катионообменной мембраны может быть превышена константа растворимости, и наиболее вероятно образование осадков сульфата кальция и карбонатов кальция и магния $[25,27]$.

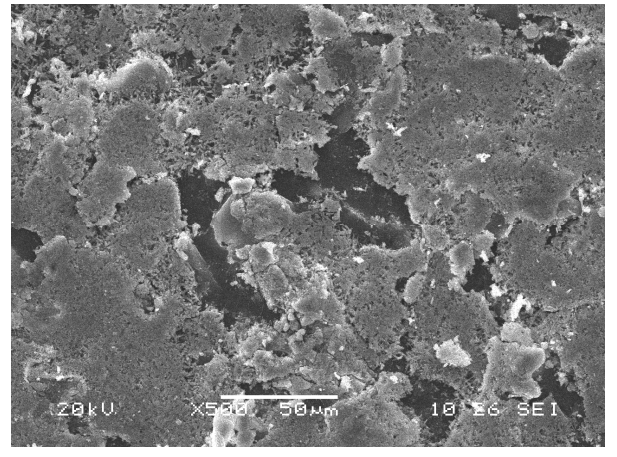

a

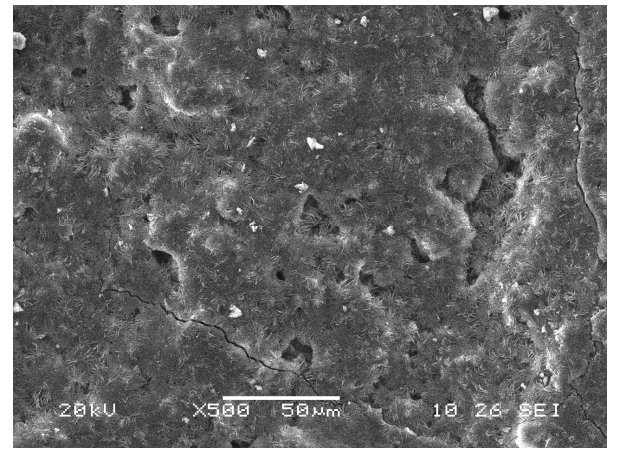

6

Рис. 2. РЭМ-изображения поверхности сухих образцов мембран МК-40 (a) и МА-40 (б) из электродных секций реверсивного электродиализного аппарата.

Карты распределения элементов на поверхности анионообменной мембраны выявили, что содержание $\mathrm{Mg}$ достигает 12.21 мас. \%, элементов Сa - 1.98 мас. \%, Fe - 0.47 мас. \% и $\mathrm{Si}-0.11$ мас. \%. Если на поверхности мембраны преимущественно образуются нерастворимые соединения $\mathrm{Mg}$, то в фазе мембраны с обеих сторон установлено образование смеси $\mathrm{CaCO}_{3}$ и $\mathrm{Ca}(\mathrm{OH})_{2}$. Взаимодействия катионов жесткости и железа с фиксированными группами мембраны МА-40 [27] и образование малорастворимых карбонатов, гидроксидов и сульфатов приводит к блокировке как функциональных групп, так и транспортных каналов мембраны [26, 28].

\section{Заключение}

Выявлены механизмы снижения селективности гетерогенных ионообменных мембран МК-40 и МА-40 при использовании в процессах деминерализации и концентрирования природных минерализованных вод методом электродиализа. Основной причиной ухудшения селективных свойств мембран, извлеченных из рабочего пакета аппарата-концентратора при концентрировании природных вод Тюменской области, следует выделить деструкцию ионогенных групп, вызывающую снижение полной обменной емкости мембран, и увеличение их макропористости в результате эксплуатации, которое сопровождается ростом влагосодержания.

Важным фактором, определяющим снижение чисел переноса противоинов ионообменных мембран из электродных секций реверсивного электродиализатора при деминерализации природных вод Аральского региона, является осадкообразование, затрагивающее поверхность и объем мембраны. Взаимодействия катионов жесткости и железа с фиксированными группами мембраны и образование малорастворимых карбонатов, гидроксидов и сульфатов приводит к блокировке как функциональных групп, так и транспортных каналов мембраны. Это вызывает снижение на $25 \%$ селективности ионообменной мембраны МА-40, извлеченной из анодной секции реверсивного электродиализного аппарата.

Работа выполнена при поддержке гранта Президента Российской Федерации MK-925.2018.3. 
Микрофотографии поверхности мембран получены на оборудовании Центра коллективного пользования Воронежского государственного университета.

URL: http://ckp.vsu.ru.

\section{Список литературы}

1. Первов А.Г., Чухин В.А., Михайлин А.В. Расчет, проектирование и применение электродиализных (электромембранных) установок по деминерализации воды. М.: МГСУ. 2012. 88 c.

2. Cifuentes-Araya N., Pourcelly G., Bazinet L. // J. Colloid Interface Sci. 2012. Vol. 372. pp. 217-230. DOI: 10.1016/j.jcis.2011.12.067

3. Casademont C., Araya-Farias M., Pourcelly G., Bazinet L. // J. Membr. Sci. 2008. Vol. 325. pp. 570-579. DOI: 10.1016/j.memsci.2008.08.023

4. Mikhaylin S., Bazinet L. // Adv. Colloid Interface Sci. 2016. Vol. 229. pp. 34-56. DOI: 10.1016/j.cis.2015.12.006

5. Firdaous L., Malériat J.P., Schlumpf J.P., Quéméneur F. // Sep. Sci. Technol. 2007. Vol. 42. pp. 931-948. DOI: $10.1080 / 01496390701206413$

6. Chen T., Neville A., Yuan M. // Chemical Engineering Science. 2006. Vol. 61. pp. 53185327. DOI: 10.1016/j.ces.2006.04.007

7. Van Geluwe S., Braeken L., Robberecht T., Jans M. et al. // Resources, Conservation and Recycling. 2011. Vol. 56. pp. 34-42. DOI: 10.1016/j.resconrec.2011.09.001

8. Andreeva M.A., Gil V.V., Pismenskaya N.D., Nikonenko V.V. et al. // J. Membr. Sci. 2017. Vol. 540. pp. 183-191. DOI: 10.1016/j.memsci.2017.06.030

9. Asraf-Snir M., Gilron J., Oren Y. // J. Membr. Sci. 2016. Vol. 520. pp. 176-186. DOI: 10.1016/j.memsci.2016.07.013

10. Нефедова Г.З., Климова З.Г., Сапожникова Г.С. Ионитовые мембраны. Грануляты. Порошки: каталог. М.: НИИТЭХим. 1977. $31 \mathrm{c}$.

11. Березина Н.П., Кононенко Н.А., Дворкина Г.А, Шельдешов Н.В. Физикохимические свойства ионообменных материалов. Краснодар: Изд-во Кубан. гос. ун-та. 1999. 82 c.

12. Larchet C., Eigenberger G., Tskhay A., Tastanov K. et al. // Desalination. 2002. Vol.149. pp. 383-387. DOI: 10.1016/S00119164(02)00836-6

13. Патент 422 (Республика Казахстан). Электродиализатор / Институт химических наук им. А.Б. Бектурова НАН РК. Цхай А.А., Ергожин Е.Е., Шерстобитов В.С. // Бюл. 1994. № 1.5 c.

14. Сайт ТОО «Мембранные технологии, C.A.» Режим доступа: http://www.mtca.kz (дата обращения 11.06.2019)

15. Гнусин Н.П., Березина Н.П. Электромембранные методы разделения и очистки растворов. Краснодар: Изд-во Кубан. гос. унта. $1986.37 \mathrm{c}$.

16. Сирота Е.А., Кранина Н.А., Васильева В.И., Малыхин М.Д. и др. // Вестн. Воронеж. гос. ун-та. Сер. Химия. Биология. Фармация. 2011. № 2. С. 53-59.

17. Васильева В.И., Акберова Э.М., Жильцова А.В., Черных Е.И. и др. // Поверхность. Рентгеновские, синхротронные и нейтронные исследования. 2013. № 9. С. 27-34.

18. Васильева В. И., Акберова Э. М., Шапошник В.А., Малыхин М.Д. // Электрохимия. 2014. Т. 50. № 8. С. 875-883.

19. Полянский Н.Г., Тулупов П.Е. // Уcneхи химии. 1971. Т. 11. Вып. 12. С. 2250-2279.

20. Тулупов П.Е., Полянский Н.Г. // Усneхи химии. 1973. Т. 42. Вып. 9. С. 1650-1680.

21. Петрова Н.И., Потапова М.А. // Журн. прикл. химии. 1969. Т. 42. № 1. С. 120-125.

22. Bauer B., Strathmann H., Effenberger F. // Desalination. 1990. Vol. 79. pp. 125-144. DOI: 10.1016/0011-9164(90)85002-R

23. Harland C.E. Ion Exchange: Theory and Practice. Cambridge: Royal Society of Chemistry. 1994.285 p.

24. Копылова В.Д., Портных Н.В., Каримова Л. В., Шабанова Л.Н. // Журн. прикл. химии. 1979. Т.52. № 3. С. 533-537.

25. Васильева В.И., Акберова Э.М., Голева Е.А., Яцев А.М. и др. // Поверхность. Рентгеновские, синхротронные и нейтронные исследования. 2017. № 4. С. 49-56.

26. Васильева В. И., Акберова Э. М., Костылев Д. В., Цхай А. А. // Мембраны и мембранные технологии. 2019. Т. 9 № 3. С. 183197.

27. Яцев А.М., Акберова Э.М., Голева Е.А., Васильева В.И. и др. // Сорбционные и хроматографические проиессы. 2017. Т. 17. 
№ $2 . \quad$ C. $313-322$.

DOI:

10.17308/sorpchrom.2017.17/386

28. Акберова Э. М., Яцев А. М., Голева Е. А., Васильева В. И. // Конденсированные

\section{References}

1. Pervov A.G., Chukhin V.A., Mikhaylin A.V. Raschet, proyektirovaniye i primeneniye elektrodializnykh (elektromembrannykh) ustanovok po demineralizatsii vody. Moskva, MGSU, 2012, 88 p.

2. Cifuentes-Araya N., Pourcelly G., Bazinet L., J. Colloid Interface Sci., 2012, Vol. 372, pp. 217-230. DOI: 10.1016/j.jcis.2011.12.067

3. Casademont C., Araya-Farias M., Pourcelly G., Bazinet L., J. Membr. Sci., 2008, Vol. 325, pp. 570-579. DOI: 10.1016/j.memsci.2008.08.023

4. Mikhaylin S., Bazinet L., Adv. Colloid Interface Sci., 2016, Vol. 229, pp. 34-56. DOI: 10.1016/j.cis.2015.12.006

5. Firdaous L., Malériat J.P., Schlumpf J.P., Quéméneur F., Sep. Sci. Technol., 2007, Vol. 42, $\quad$ pp. 931-948. DOI: 10.1080/01496390701206413

6. Chen T., Neville A., Yuan M., Chemical Engineering Science, 2006, Vol. 61, pp. 53185327. DOI: 10.1016/j.ces.2006.04.007

7. Van Geluwe S., Braeken L., Robberecht T., Jans M. et al., Resources, Conservation and Recycling, 2011, Vol. 56, pp. 34-42. DOI: 10.1016/j.resconrec.2011.09.001

8. Andreeva M.A., Gil V.V., Pismenskaya N.D., Nikonenko V.V. et al., J. Membr. Sci., 2017, Vol. 540, pp. 183-191. DOI: 10.1016/j.memsci.2017.06.030

9. Asraf-Snir M., Gilron J., Oren Y., J. Membr. Sci., 2016, Vol. 520, pp. 176-186. DOI: 10.1016/j.memsci.2016.07.013

10.Nefedova G.Z., Klimova Z.G., Sapozhnikova G.S. Ionitovye membrany. Granulyaty. Poroshki: catalog, M., NIITEKhim, 1977, 31 p.

11.Berezina N.P., Kononenko N.A., Dvorkina G.A, Shel'deshov N.V. Fiziko-khimicheskiye svoystva ionoobmennykh materialov. Krasnodar, Izd-vo Kuban. gos. un-ta, 1999, 82 p.

12.Larchet C., Eigenberger G., Tskhay A., Tastanov K. et al., Desalination, 2002, Vol 149, pp. $\quad 383-387 . \quad$ DOI: $10.1016 /$ S00119164(02)00836-6

13.Patent 422 (Respublika Kazakhstan). Elektrodializator / Institut khimicheskikh nauk im. A.B. Bekturova NAN RK., Tskhay A.A., Yer- gozhin Ye.Ye., Sherstobitov V.S., Byul. 1994, No 1, 5 p.

14. Website of Membrane Technologies, S.A. Available at: http://www.mtca.kz (accessed 11 June 2019)

15.Gnusin N.P., Berezina N.P. Elektromembrannye metody razdeleniya i ochistki rastvorov. Krasnodar, Izd-vo Kuban. gos. un-ta, 1986, $37 \mathrm{p}$.

16.Sirota E.A., Kranina N.A., Vasil'eva V.I., Malykhin M.D. et al., Vestn. Voronezh. gos. unta. Ser. Khimiya. Biologiya. Farmatsiya, 2011, № 2, pp. 53-59.

17. Vasil'eva V.I., Akberova E.M., Zhiltsova A.V., Chernykh E.I. et al., J. of Surface Investigation. X-ray, Synchrotron and Neutron Techniques, 2013, Vol. 7, No 5, pp. 833-840. DOI: 10.1134/S1027451013050194

18. Vasil'eva V.I., Akberova E.M., Shaposhnik V.A., Malykhin M.D., Russ. J. Electrochem, 2014, Vol. 50, pp. 789-797. DOI: 10.1134/S102319351408014X

19.Polyanskiy N.G., Tulupov P.E., Uspekhi khimii, 1971, Vol. 11, No 12, pp. 2250-2279.

20.Tulupov P.E., Polyanskiy N.G., Uspekhi khimii, 1973, Vol. 42, No 9, pp. 1650-1680.

21.Petrova N.I., Potapova M.A., Zhurn. prikl. khimii, 1969, Vol. 42, No 1, pp. 120-125.

22.Bauer B., Strathmann H., Effenberger F., Desalination. 1990. Vol. 79, pp. 125-144. DOI: 10.1016/0011-9164(90)85002-R

23.Harland C. E. Ion Exchange: Theory and Practice. Cambridge: Royal Society of Chemistry, 1994. 285 p.

24.Kopylova V.D., Portnykh N.V., Karimova L.V., Shabanova L.N., Zhurn. prikl. khimii, 1979, Vol. 52, No 3, pp. 533-537.

25. Vasil'eva V.I., Akberova E.M., Goleva E.A., Yatsev A.M. et al., J. of Surface Investigation. X-ray, Synchrotron and Neutron Techniques, 2017, Vol. 11, No 2, pp. 49-56. DOI: $10.1134 / \mathrm{S} 1027451017020367$

26. Vasil'eva V.I., Akberova E.M., Kostylev D.V., Tzkhai A.A., Membranes and Membrane Technologies, 2019, Vol. 9, No 3, pp. 183-197. DOI: $10.1134 / \mathrm{S} 2517751619030077$ 
27.Akberova E.M., Yatsev A.M., Goleva E.A., Vasil'eva V.I. et al., Sorbtsionnye $i$ khromatograficheskie protsessy, 2017, Vol. 17, No 10.17308/sorpchrom.2017.17/386

Акберова Эльмара Маликовна - к.х.н., ведущий инженер кафедры аналитической химии, Воронежский государственный университет, Воронеж.

Васильева Вера Ивановна - д.х.н., професcop кафедры аналитической химии, Воронежский государственный университет, Воронеж

Смагин Михаил Алексеевич - студент химического факультета, Воронежский государственный университет, Воронеж

Костылев Денис Викторович - студент химического факультета, Воронежский государственный университет, Воронеж
28.Akberova E.M., Yatsev A.M., Goleva E.A., Vasil'eva V.I., Kondensirovannyye sredy $i$ mezhfaznyye granitsy, 2017, Vol. 19, No 3, pp. 451-462.

Akberova Elmara M. - PhD (Chem.), a leading engineer of the Analytical Chemistry Department, Voronezh State University, Voronezh, e-mail: elmara 09@inbox.ru

Vasil'eva Vera I. - Dr. Sci. (Chem.), a professor of the Analytical Chemistry Department, Voronezh State University, Voronezh, e-mail: viv155@mail.ru

Smagin Mikhail A. - a student of the Chemical Faculty, Voronezh State University, Voronezh

Kostylev Denis V. - a student of the Chemical Faculty, Voronezh State University, Voronezh 